\title{
ALGUNS DISCURSOS DA PEDAGOGIA SOB ANÁLISE: CIÊNCIA MODERNA E REDUPLICACÃO DO HOMEM ${ }^{1}$
}

\author{
SOME DISCOURSES OF PEDAGOGY UNDER ANALYSIS: MODERN SCIENCE AND MAN \\ REDUPLICATION
}

Paula Corrêa Henning Doutora em Educação pela UNISINOS. Docente dos Programas de Pós-graduação em Educação Ambiental e Educação em Ciências da FURG.

Bárbara Hees Garré Doutoranda em Educação Ambiental pela FURG. Programa de Pós-Graduação em Educação Ambiental Universidade Federal do Rio Grande (FURG)

Rio Grande - RS - Brasil

Endereço:

Av. Itália, s/n, Km 08 Carreiros - Rio Grande - RS CEP: $96201-900$

E-mails:

paula.henning@ig.com.br barbaragarre@gmail.com

RESUMO

O artigo busca problematizar alguns discursos de ciência muito potentes e que ganham força no cenário da Pedagogia a partir da década de 80 . Analisamos duas obras recorrentes na formação do pedagogo, as quais tratam a Pedagogia como a ciência da educação. Utilizamos como campo teórico desse estudo especialmente Michel Foucault, colocando em discussão os efeitos produzidos por alguns ditos que atravessam, inventam e produzem esse campo de saber. Problematizamos o presente, entendendo que ele é produzido por alguns discursos que buscam a legitimação da Pedagogia como uma ciência humana. Nesse texto, abordamos alguns conceitos de Ciência Moderna que atravessam e constituem a Pedagogia como a ciência da educação; problematizamos os discursos de reduplicação do homem, os quais ganham força e produtividade nesse campo de saber, tornando-se a condição de possibilidade para que as ciências humanas emerjam como ciências. Provoca-se o leitor a pensar no nosso fazer docente, ao colocarmos em dúvida verdades que por muito tempo também nos habitaram.

PALAVRAS-CHAVE: Educação. Pedagogia. Ciências Humanas.

ABSTRACT

This article seeks to problematize some very powerful speeches of science and gain strength in the scenario of Pedagogy from the 80s. We analyze two works of teacher training applicants in dealing Pedagogy as a science of education. We use this study as a theoretical especially Michel Foucault, discussing the effects produced by some sayings that cross, invent and produce this field of knowledge. Problematize this, understanding that it is produced by some discourses that seek legitimization of education as a human science. In this text we discuss some concepts of modern science that cross and form Pedagogy as a 
science education; problematize the discourses of reduplication man's earning power and productivity of knowledge in this field, making it a condition of possibility for the humanities emerge while science. Provokes the reader to think our teachers do put in doubt the truths that had long dwelt in also.

KEYWORDS: Education. Pedagogy. Humanities.

\section{DELIMITANDO O OLHAR}

O artigo aqui apresentado tem a intenção de problematizar alguns discursos de ciência muito potentes e que ganham força no cenário da Pedagogia a partir da década de 80, época em que as pesquisas educacionais buscavam com mais veemência a legitimação e o reconhecimento científico. Assim, escolhemos colocar luz em duas obras que tratam a Pedagogia como a ciência da educação e que são recorrentemente utilizadas em cursos que formam pedagogos, são elas: "Pedagogia: ciência da Educação?"2 e "Pedagogia como ciência da Educação"3.

A escolha por tal temática não é ingênua, muito pelo contrário, é uma escolha que está relacionada à nossa profissão, a algumas questões que nos tocam e que nos despertam uma vontade de saber, podemos dizer que é uma escolha governada por nossas vontades de verdade. Operamos com conceitos de ciência, episteme moderna, regime de verdade, ordem discursiva, entre outros para problematizar a constituição científica da Pedagogia.

As problematizações que passaremos a provocar se situam no nível do discurso, simplesmente referindo-se ao que está dito, não estamos preocupadas em interpretar, descobrir ou desvelar os discursos de ciência que constituem a Pedagogia. Queremos, sim, colocar em discussão os efeitos produzidos por alguns desses ditos que atravessam, inventam e produzem esse campo de saber. Para tanto, operamos com o conceito de discurso a partir do filósofo francês Michel Foucault. Por entender que estes discursos que reivindicam o status de ciência à Pedagogia são muito fortes no cenário Educacional e encontram reverberação na formação destes profissionais é que trabalhamos com eles. Nosso percurso aponta na tentativa de operar com os efeitos produzidos por estes ditos, que legitimam a Pedagogia como campo de saber científico. Dessa forma, olhamos para a ciência, aqui especialmente as ciências humanas, como uma produção discursiva na ordem do saber vigente em nossa sociedade.

Nesta correnteza, importa destacar que não estamos colocando os autores das obras em estudo sob análise, não os tomamos como os criadores ou os inventores dos discursos. Mais importante do que o autor é o próprio discurso. E tomamos essa posição, pois, assim como Foucault, não nos interessa quem fala (FOUCAULT, 2001). Não estamos interessadas aqui com o autor, ele não é o produtor, nem o inventor dessa obra. Esses discursos estão marcados por uma ordem mais ampla na qual o próprio autor é capturado por ela. Por isso, muito mais importante que saber quem é o autor, o que importa aqui são os ditos, o próprio discurso. Aqui "o autor, não entendido, é claro, como o indivíduo falante que pronunciou ou escreveu um texto, mas o autor como o princípio de agrupamento do discurso, como unidade e origem de suas significações, como foco de sua coerência" (FOUCAULT, 2004, p. 26).

Ao colocarmos a Pedagogia em estudo, não queremos reconstituir a "grande história da Pedagogia" ou dos "Saberes Pedagógicos" que foram construídos. Nossa pretensão é bem mais modesta do que esta. É a intenção de problematizar o presente, entendendo que este presente foi produzido por alguns discursos, alguns atravessamentos, algumas condições de possibilidade que buscam a legitimação da Pedagogia como uma ciência humana.

Escolhemos trabalhar numa perspectiva micropolítica por entendermos que somos seres deste mundo, capazes de realizarmos algumas coisas e não outras, não temos condições de dar conta de um universo, de sermos a "voz da consciência" de uma sociedade. Percebemo-nos como profissionais, pesquisadoras, que têm condições de dar conta de algumas questões bem mais locais, bem mais restritas, mas que nos produzem algum efeito, nos inquieta de alguma forma.

Sabemos que, ao fazer tal escolha, estamos correndo o risco, estamos também nos colocando em exame, uma vez que a Pedagogia constitui nosso campo de atuação profissional. Fazer tal 
escolha não é nada fácil, pois precisamos deixar algumas verdades em suspenso, olhar com desconfiança para crenças e conviç̧ões que nos acompanharam por muito tempo e nos produziram nas profissionais que hoje somos.

Dadas estas primeiras balizas, passamos a tratar a questão da Pedagogia como ciência. Nos livros analisados, podemos dizer que duas unidades de análise emergiram com muita força, são elas: marcas da ciência moderna e reduplicação do homem. Na primeira, aparecem enunciados como "racionalidade da prática", "método científico", "dialética", entre outros. No que se refere à segunda, são emblemáticos os enunciados que reverberam uma "ciência da prática educativa", uma "reflexão sobre a prática" e um "exame das práticas educativas".

Alguns questionamentos nos passam, instiga-nos pensar o que faz com que tais discursos científicos ganhem reverberação no campo da Educação? O que move a Pedagogia pela busca de ser legitimada como ciência? Que ciência é esta que nós pedagogos estamos reivindicando? Por que não pensarmos em outras possibilidades de produção de saber que não pelo viés exclusivo a ciência? Não queremos com isto questionar ou negar a ciência, muito pelo contrário, nosso questionamento não perpassa questões reducionistas de olhar a ciência como boa ou ruim. Olhamos a ciência como algo produtivo, pois esta produz saber. Entretanto não é a única possibilidade de produção de saber. O que nos move é problematizar o campo da ciência e a entrada da Pedagogia Moderna como a ciência da educação.

Para isso, nosso artigo está distribuído em três momentos, na intenção de organizá-lo articulando as ideias e evidenciando as unidades de análises que nos foram possíveis constituir. Primeiramente, abordamos alguns conceitos de Ciência Moderna que atravessam e constituem a Pedagogia como a ciência da educação. Logo em seguida, passamos a problematizar os discursos de reduplicação do homem que ganham força e produtividade nesse campo de saber, tornandose a condição de possibilidade para que as ciências humanas, e aqui, em especial, a Pedagogia, emerjam como ciências. Na tentativa de colocar um ponto final no artigo, provocamos o leitor - e a nós mesmas - para pensar algumas possibilidades de colocar em suspenso a forma moderna de fazer ciência no campo da Pedagogia.

\section{A PEDAGOGIA ATRAVESSADA PELAS MARCAS DA CIÊNCIA MODERNA}

A ciência não se contenta em invadir e transtornar nosso meio ambiente com os objetos técnicos cuja criação ela possibilita e que vemos se reproduzirem e renovarem à nossa volta num ritmo exponencial: após haver cercado o trabalho, os transportes, o lazer, a vida doméstica, a saúde dos corpos ou a comunicação dos espíritos, a tecno-ciência insinua-se até em nossas maneiras de calcular e de pensar (microcomputadores), de fazer amor (pílula anticoncepcional), de dar a vida ou de ir para a morte (bio- ou tanato-tecnologias)... (CHRÉTHIEN, 1994, p. 17).

Em nossas sociedades, cada vez mais, vemos a emergência da ciência nas nossas vidas cotidianas. Somos provocados a entrar no fluxo propagador da ordem científica vigente, que nos interpela minuto a minuto, seja em relação as nossas práticas profissionais, as nossas formas de nos relacionar ou até mesmo em nossos hábitos mais corriqueiros, como comprar um determinado produto de limpeza ou escolher a marca da tinta de cabelo (que promete cabelos saudáveis e brilhosos). Desta forma, podemos dizer que a ciência intervém ativamente em nossas escolhas e vai conduzindo nossas formas de ser e viver o contemporâneo.

Pensando sobre a educação, mais especificamente a Pedagogia - foco de nossa discussão - não poderíamos entender de forma diferente, pois a ciência atravessa e produz esse campo de saber de formas diversas, em múltiplas frentes. Constantemente, convida os professores a entrar e participar deste espaço científico que legitima saberes, tais como: testando determinado método de ensino; utilizando esse ou aquele livro didático; experimentando novas metodologias de aprendizagem; conhecendo e inserindo as novas tecnologias da informação e da comunicação na sala de aula.

Ao assistirmos às chamadas de propagandas veiculadas na televisão, na Internet, nas revistas em geral, incitando os professores na busca de qualificação, sendo avaliados por provas ${ }^{4}$ e exames que estabelecem o ranking dos melhores, nos provocamos a pensar: que estratégias estão sendo colocadas em operação? Vemos aqui uma importante tecnologia de poder sendo colocada em funcionamento, esta tecnologia é o que Michel Foucault (1985; 1990; 2005; 2008a; 2008b) chamou 
de biopoder - um poder sobre a vida da população, aqui especificamente a população de professores. Esta relação de poder se dá no nível da coletividade e sua reverberação encontra no saber legitimado pela ciência uma potência constituidora de verdades. Nessas propagandas midiáticas, o que vemos muitas vezes são divulgações dos números, como os índices do nível de alfabetização no país, enfim, de estatísticas que são apresentadas e têm como objetivo a comprovação - e vale dizer também a fabricação - de algumas verdades. Assim, por meio da estatística, importante ferramenta de legitimação científica, nomeia-se o certo e o verdadeiro que podem ser verificados pelos dados quantitativos, pelos "dados reais" que mostram as pesquisas.

Percebemos em tais estratégias de captura do professorado, o quanto é necessário comprovar para a sociedade, em números, em resultados, a eficácia do trabalho realizado. É a potência da ciência matemática que cada vez ganha mais visibilidade. Assim, a ciência que vai sendo produzida nas áreas de saber da educação se pauta pelos princípios norteadores de uma racionalidade típica da Ciência Moderna, que tem como princípios fundamentais aqueles constituídos com base nas Ciências Exatas - comprovação dos fenômenos; observação e experimentação; universalização dos saberes; controle do mundo pelo homem.

Assim, provocamo-nos questionar a ciência como o único modo válido de saber. Na contramão dessas metanarrativa, a entendemos como uma construção humana, feita por homens e mulheres deste mundo, assim como tantas outras produções de saber, tais como a arte e a cultura. Inquietanos ser esta a única possibilidade de se fazer ciência, seguindo os passos lineares da Ciência Moderna. Talvez este seja o desafio a que nos propomos ao olhar a Pedagogia atravessada por alguns discursos da Ciência Moderna: o desafio de produzirmos uma linha de fuga, uma forma de escapar, minimamente, que seja da forma vigente de se fazer pesquisa.

Em se tratando da Pedagogia como uma das ciências humanas ou a ciência da educação, como reivindicam alguns autores ${ }^{5}$, percebemos o quanto ela é considerada uma ciência mole. Isto se deve porque estas ciências não têm um objeto concreto, observável e quantificável, assim são consideradas ciências de menor relevância ainda no cenário atual, pois lidam com a subjetividade humana. Além disso, as ciências ditas sociais constituem-se a partir dos pressupostos científicos das ciências exatas. Seguem o modelo de pesquisa científica de validação do conhecimento a partir dos métodos de estudo e, muitas vezes, de análises positivistas. Nesta correnteza, situamos a Pedagogia que, para se fazer ciência, segue o modelo do método científico, como podemos constatar nos excertos destacados:

\begin{abstract}
A pedagogia, para se fazer ciência, precisou adequar-se à lógica que presidia a ciência da época e isso implicou sistematizar sua ação prática, com base nas teorizações dos experimentos possíveis ao momento histórico, realizados e presididos por outros profissionais, inicialmente os psicólogos que, por força de sua formação, dominavam o manuseio de instrumentos experimentais. Isso acarretou um caminhar da pedagogia da direção da não-consideração do saber-fazer da prática educativa, território do exercício artesanal dos artistas da prática, quais sejam, os educadores, pedagogos e professores. Dessa forma ela se organiza como ciência empírica, limitando o exercício artístico de seu objeto de estudo, qual seja, a prática educativa (FRANCO, 2003, p. 26) [grifos nossos]. ${ }^{6}$
\end{abstract}

Nessa pesquisa fiz descobertas interessantes que fundamentaram minha hipótese de que o princípio de cientificidade, estruturado pós-Herbart, foi gradativamente impondo um fechamento de horizontes à pedagogia de tal forma que, para ser ciência, teve que deixar de ser pedagogia, ciência da educação, pois este objeto (a educação) foi se restringindo à instrução, ao visível, ao aparente, ao observável do ensino, a fim de poder ser aprendida pela racionalidade científica que a pressupunha. (FRANCO, 2003, p. 58). [grifos nossos].

Considerando-se que a racionalidade se funda nos princípios acima e constrói-se ao longo da história, pode-se dizer que a Pedagogia, condição racional da prática educativa, se faz por meio das teorias - inclusive as antagônicas - que se apresentam em sua história. (PIMENTA, 2006, p. 26) [grifos nossos].

Conhecimento, observação, racionalização e descrição dos fenômenos educativos são enunciados que constituem a prática científica dos pedagogos. Assim, entendemos que os excertos acima são emblemáticos para se pensar o caminho seguido pela Pedagogia, que busca um reconhecimento, uma etiqueta de ciência. Para tanto, se torna uma ciência que tem como princípio tornar a prática racional, conhecer para transformar, para melhorar, na busca do avanço e do progresso, emblemas 
tão propagados e disseminados pelas ciências positivistas. Seguindo estes passos, a Pedagogia assume-se como uma ciência de observação e de experimentação, construindo assim as bases para a produção de uma prática pedagógica universal, dogmática e totalizadora.

Interessante destacar que a Pedagogia, ao mesmo tempo em que busca legitimar-se como ciência a partir dos princípios de uma ciência pautada na lógica positivista, lida com a subjetividade de seu objeto de estudo, que não é tão certo, tão previsível como o objeto das ciências duras. Assim, busca na teoria da dialética a possibilidade de fazer aparecer aquilo que está escondido, mostrando a existência de dois mundos, o objetivo e o subjetivo. Isto se torna visível nos seguintes recortes:

\begin{abstract}
A educação é uma prática social humana; é um processo histórico, inconcluso, que emerge da dialeticidade entre homem, mundo, história e circunstâncias. Sendo um processo histórico, a educação não poderá ser apreendida por meio de estudos metodológicos que congelam alguns momentos de sua prática. Deverá o método dar conta de aprendêla em sua dialeticidade, captando não apenas as objetivações de uma prática real concreta, mas a potencialidade latente de seu processo de formação. (FRANCO, 2003, p. 73) [grifos nossos].
\end{abstract}

O fazer pedagógico é inevitavelmente um fazer investigativo. Quando superamos a concepção de prática como tecnologia da prática e adentramos na dialética da práxis, não há outro caminho. (FRANCO, 2003, p. 116) [grifos nossos].

A ciência da educação será dialética na medida em que, partindo do interesse libertário do conhecimento de uma teoria crítica da sociedade, voltado a emancipação e libertação dos homens (humanização), tornar possível a ela (a Pedagogia) a antecipação de uma práxis educacional transformada. (PIMENTA, 2006, p. 53) [grifos nossos].

No corpus discursivo em análise, os discursos científicos ganham força e carregam um estatuto de verdade, garantindo que algumas vozes estejam autorizadas a falar e sejam escutadas. Vemos nestes ditos que não é qualquer um a falar de qualquer coisa. Aqui, os pedagogos são nomeados e autorizados a falar da escola, da aprendizagem, das práticas educativas. Entendemos, então, que algumas estratégias de poder-saber são colocadas em operação, ao eleger os pedagogos como os sujeitos capazes de produzir pesquisas no cenário educacional e selecionar, o que conta como verdadeiro.

O exercício de uma prática reflexiva requer a presença contínua, crítica e construtiva do pesquisador educacional, que reconheço como o pedagogo. Essa presença se faz necessária tanto para a construção de um ambiente investigativo - que permita e favoreça uma cultura de pesquisa, de forma a produzir conhecimentos científicos que estejam continuamente fertilizando e referenciando essas práticas -, como também na reconstrução e na construção de novas e atualizadas concepções da prática educativa (FRANCO, 2003, p. 99).

A atuação do pedagogo escolar é imprescindível na ajuda aos professores no aprimoramento de seu desempenho na sala de aula (conteúdos, métodos, técnicas, formas de organização da classe), na análise e compreensão das situações de ensino com base nos conhecimentos teóricos, ou seja, na vinculação entre as áreas do conhecimento pedagógico e o trabalho de sala de aula (PIMENTA, p. 127).

Assim, entendemos que o discurso da ciência pedagógica encontra seu campo de exercício sobre as práticas escolares, conduzindo e direcionando as condutas individuais e coletivas. Vemos nesse exercício que a formação de um determinado tipo de saber é fundamental para garantir a este profissional o reconhecimento de quem tem a primazia de enunciar a verdade. Aqui, estamos entendendo a verdade como um efeito discursivo, verdade que é produzida e legitimada dentro de determinada episteme e que vai constituindo as formas de ser e viver na atualidade. Foucault entende por verdade "o conjunto de procedimentos que permitem a cada instante a cada um pronunciar enunciados que serão considerados verdadeiros" (2006, p. 233). Dessa forma, olhamos para a verdade como uma fabricação que se dá a partir da seleção de discursos que colocam alguns ditos "no verdadeiro" e outros não.

Visualizamos na Pedagogia um campo de saber que é legitimado a falar sobre as questões educativas e a partir disso produzir verdades ao mesmo tempo em que é produzida por elas. Então, será possível fugir dessa proliferação discursiva? É possível pensar a Pedagogia escapando da ordem do discurso científico? Nossa tentativa é pensarmos na possibilidade de vivermos nesse mundo, 
produzindo nossas vidas públicas e privadas a partir daquilo que construímos e a partir daquilo que conseguimos romper. Olhamos para o mundo, para a ciência, para a Pedagogia como construções humanas, que produzem verdades, mas não queremos com isto nomear o bem e o mal. Muito pelo contrário, queremos abrir mão de qualquer juízo de valor, entendendo a ciência como um campo de produções, como a possibilidade de produzirmos outro modo de vida e, quem sabe, uma outra forma de fazer ciência que seja mais alegre e mais provocativa.

Vale a provocação... A inquietação do pensamento. Para seguirmos a correnteza do estudo, passamos à análise do segundo extrato para pensarmos o corpus discursivo aqui selecionado: a reduplicação do homem nas ciências humanas, mais especialmente, no campo da Pedagogia.

\section{A PEDAGOGIA COMO CIÊNCIA DA REDUPLICAÇÃO DO HOMEM}

No movimento em que vimos trabalhando nesse artigo, entendemos ser importante situar as ciências humanas, já que entendemos a Pedagogia como sendo uma dessas ciências do homem. Para tanto, tornar-se necessário retomarmos algumas questões centrais na discussão de ciência, principalmente nos três últimos séculos. A palavra ciência nos remete a quê? Quando pensamos em cientistas, quais profissões são comumente lembradas? Outra provocação: ciência ou ciências? O que seria um conhecimento científico? Como um conhecimento se torna científico? Estas questões nos acompanham, nos causam inquietações e nos provocam a pensar no contexto em que as ciências humanas se constituíram.

As ciências humanas emergem a partir das ciências exatas, entretanto com o estigma de ciências fracas ou ciências moles, como apontam alguns autores. Esta denominação se dá porque estas ciências do homem trabalham com a subjetividade, com algo que escapa aos padrões construídos como científicos, de manipulação, comprovação e validação dos fenômenos. Entretanto, é conferido às ciências humanas desenvolver saberes sistemáticos e racionais sobre o homem, que acabam por se tornar sujeito e objeto de sua própria investigação. Percebemos com isso que as ciências humanas acabam por pautar seus estudos a partir dos princípios das ciências ditas duras. Os excertos abaixo são emblemáticos para pensarmos como a Pedagogia se produziu a partir de um modelo científico legitimado pelas Ciências Exatas:

Admitindo que nenhuma ciência se constitui sem que se saiba qual é o seu campo, indagase qual é o campo da pedagogia, o real pedagógico. Afirma que o conhecimento do real constitui uma primeira etapa do método científico e que uma forma de conhecê-lo é observá-lo, para, a seguir, descrevê-lo. Por isso, propõe a necessidade da descrição dos fenômenos pedagógicos, com instrumentos métodos próprios (PIMENTA, 2006, p. 44) [grifos nossos].

Assim, a pedagogia, como ciência emergente da época, não poderia escapar de assumir essa nova identidade epistemológica de se fazer produtora de tecnologia, racionalizando ações pedagógicas e distanciando-se de reflexões sobre valores voltados à boa convivência, à compreensão de processos ético-sociais, à interpretação e à fundamentação de novos sentidos de solidariedade e justiça entre os homens. (FRANCO, 2003, p.34) [grifos nossos].

Aqui a Pedagogia é assumida então como a ciência que estuda os fenômenos educativos, os observa, descreve e interpreta. Assim como nas ciências duras, é necessário ter uma visão da realidade, uma visão dos objetos a descrever e critérios para validação de tais objetos como científicos ou não. Dessa forma, parece que a Pedagogia vai se constituindo como a ciência que estuda as práticas educativas a partir desse viés positivista. A Pedagogia, sendo esta ciência da prática educativa, deve conhecer e desenvolver saberes sobre a escola, os professores, os alunos, a aprendizagem, enfim tudo que se relaciona a tal prática. Precisa desenvolver cada vez mais estes saberes, conhecer profundamente cada passo, cada ação, estabelecendo estrategicamente as intervenções necessárias, conduzindo as condutas individuais e coletivas para o caminho do bem, o caminho do conhecimento verdadeiro.

De um modo mais geral, o homem, para as ciências humanas, não é esse ser vivo que tem uma forma bem particular (uma fisiologia bastante especial e uma anatomia quase única); é esse ser vivo que, do interior da vida à qual pertence inteiramente e pela qual é atravessado em todo seu ser, constitui representações graças às quais ele vive e a partir das quais detém essa estranha capacidade de poder se representar justamente a vida. (FOUCAULT, 2002a, p. 487). 
Os discursos das Ciências Humanas vêm aparecendo desde o século XIX, colocando o homem em dupla posição - objeto do conhecimento e sujeito conhecedor. A preocupação dessas ciências reside no desejo de conhecer o homem. A partir de Foucault (2002b), podemos dizer que as Ciências Humanas nascem na tentativa de conhecer melhor o homem, para melhor governá-lo. Quanto mais saberes se desenvolvem sobre ele, quanto mais souber sobre seu funcionamento, melhores estratégias adquirem-se para controlá-lo. O que é a Pedagogia se não saberes desenvolvidos sobre o homem para produzi-lo como um ser dócil e controlado? Os saberes que se desenvolvem sobre o homem são então um instrumento daquilo que Foucault denominou de Política de Normalização, trazendo a disciplina e o biopoder como tecnologias para controlar a população. Não é à toa que a Pedagogia busca a legitimidade de seus saberes, requerendo o amparo da cientificidade moderna e é considerada como ciência do homem.

O homem assume então a posição de sujeito que conhece e objeto a conhecer, tendo a difícil tarefa de colocar-se a pensar sobre si mesmo e elaborar conhecimentos científicos na ordem do saber sobre si. Enfim, essas ciências se constituem no "estudo sobre o homem enquanto ele representa a vida em que está inserida sua existência corpórea, a sociedade em que realiza seu trabalho e o sentido de sua linguagem" (MACHADO, 2004, p. 26). Importa dizer que não é simplesmente o fato de estudar o Homem como ser vivo, seus modos de produzir riqueza e suas palavras o que caracteriza as Ciências Humanas, mas o homem tomado em sua dupla condição de sujeito que conhece e objeto do conhecimento, ao mesmo tempo em que produz representações sobre sua própria condição.

Nesse sentido, encontramos fortes anúncios pedagógicos que ratificam tal posição, enquanto aquele que se esforça para conhecer e, conhecendo, reencontra-se consigo próprio. Queremos evidenciar aqui que a produção das ciências humanas somente foi/é possível devido a essa reduplicação, não há como escaparmos dela. E entendemos que isso não é um problema a ser resolvido. A representação torna-se a condição de possibilidade para a produção das nossas ciências, ou seja, por tratarmos como nosso objeto aquilo que é nossa condição de possibilidade.

Os saberes que se produzem sob a égide das ciências humanas são produzidos nesse campo não porque estudam o homem, mas porque estudam as representações que fazemos sobre o homem como sujeito aprendente, aquele sobre o qual a ciência pedagógica debruça seu olhar. Representamos os modos como o homem olha para a sua própria condição de aprendente. A Pedagogia não se preocupa apenas com o produto da ação educativa, mas com todos os supostos mecanismos, modos, processos que levam o homem a ocupar essa posição duplicada, como alguém que conhece a respeito de sua própria condição de conhecedor.

Nesse sentido, a representação não é apenas um objeto de estudo, mas muito mais do que isso: a representação é o solo próprio de todas as ciências humanas; aquilo que as define. A razão humana é concebida como capaz de representar, de apreender o mundo na forma de uma representação humanamente construída, por meio da nossa consciência. Por isso, a representação é o grande solo do qual se erguem as ciências humanas, ela é, enfim, a condição de possibilidade para sua existência.

Ao olharmos os materiais de análise, percebemos nos livros uma ciência pedagógica preocupada com uma reflexão sobre a prática, com um exame dessas práticas. Nesses exemplares, livros que se tornam referências para o estudo da Pedagogia como ciência da educação, anuncia-se uma ciência que se efetiva através da dimensão "experiencial" da formação, assumindo-se de maneira tácita que o conhecimento se dá pela consciência que o próprio agente das práticas toma a respeito de si. Refundase a cada prática reflexiva a duplicação própria à produção do conhecimento no campo das Ciências Humanas. No par reflexão-ação encontra-se o sujeito com consciência epistemológica de sua prática. Esse mesmo sujeito que conhece se constitui como alvo desta consciência. Nele mesmo os dois polos: reflexão e ação. O conhecimento, portanto, seria produzido numa espécie de epistemologia da prática, modo característico das Ciências Humanas e de tão forte penetração nas pesquisas educacionais.

\footnotetext{
Dessa forma, cabe à ciência da educação reconhecer que, ao lado das características observáveis do fenômeno, existe um processo de transformação subjetiva, que não apenas modifica as representações dos envolvidos, mas produz uma ressignificação na interpretação do fenômeno vivido, o que produzirá uma reorientação nas ações futuras. Será fundamental que o método da ciência pedagógica abra espaço para que os sujeitos envolvidos tomem consciência do significado das transformações que vão ocorrendo em seu processo histórico (FRANCO, 2003, p. 73) [grifos nossos].
} 
Essa dimensão, de resgatar ao homem sua condição de exercício do humano, se fará tanto mais educativa a sociedade se fizer. $E$ a sociedade se fará educativa quando se utilizar do potencial educacional da sociedade, agregando-Ihe intencionalidade, explícita e coletivamente construída, cientificando seu fazer, responsabilizando-se por sua ação. A mediação que transformará o educacional em educativo se fará pela ação científica, crítica e reflexiva da pedagogia, como ciência da educação. (FRANCO, 2003, p. 111) [grifos nossos].

\begin{abstract}
A atuação do pedagogo escolar é imprescindível na ajuda aos professores no aprimoramento de seu desempenho na sala de aula (conteúdos, métodos, técnicas, formas de organização da classe), na análise e compreensão das situações de ensino com base nos conhecimentos teóricos, ou seja, na vinculação entre as áreas do conhecimento pedagógico e o trabalho de sala de aula. (PIMENTA, p. 127) [grifos nossos].
\end{abstract}

A crítica a Pedagogia tem aumentado: ela não cobriria os requisitos de "cientificidade"; seria uma tarefa voltada para a prática, estando mais no campo da intuição e da arte do que no campo cientifico; não teria objeto de estudo próprio porque o fenômeno educativo é pluridimensional, assim como não disporia de um sistema claro e coerente de conceitos. Em primeiro lugar, algumas dessas limitações são atribuíveis às Ciências Sociais em geral. Segundo, os críticos da Pedagogia não percebem que a ocorrência dessas dificuldades epistemológicas não constituem razão suficiente para se ignorar a atividade prática correspondente ao campo de conhecimento pedagógico. Tal atividade, definida especificamente como formação humana, envolve dimensões da teoria cientifica e da prática, reflexão e ação. (PIMENTA, 2006, p. 130, 131) [grifos nossos].

Sendo a consciência o elemento fundamental dessa epistemologia particular, a linguagem assume um papel preponderante, já que é a partir dela que são produzidas as representações do sujeito cognoscente. Daí a importância de "falar", "ouvir", em resumo, narrar as experiências para poder submetê-las à ação da consciência soberana que pretende fundar sua própria verdade sobre o real.

Na tradição educacional, dada sua vocação para a produção do sujeito moral, tal epistemologia acaba sendo de grande valor, pois se consegue fazer, ao mesmo tempo, a pesquisa e a formação pautadas pelo crivo da ciência. Aqui aparece claramente um dos efeitos das Ciências Humanas como ordem discursiva moderna sobre os discursos educacionais. A eficiência dos discursos educacionais, como operadores da modernidade ética e política dá-se em função de sua ampla penetração no cotidiano das vidas dos sujeitos que dela fazem parte. Com isso, o controle sobre a vida se produz de maneira sutil não mais submetida a mecanismos disciplinares tão óbvios e visíveis, mas por meio de estratégias que apelam para a intimidade da consciência dos próprios sujeitos, um lugar tanto menos visível quanto mais eficaz para o controle das condutas.

Com as análises que fomos exercitando, percebemos que a ciência pedagógica produz o homem, que se enrolando sobre si mesmo se produz como esse duplo empírico-transcendental. É que quando ele olha para esses materiais, que são seus objetos de estudo, ele termina por olhar a si mesmo. O objeto que conhece é ele próprio, em sua forma finita. Com isso, queremos dizer que as descobertas feitas pelo homem sobre seu objeto empírico terminam sendo descobertas sobre si mesmo, ou como diria Foucault, descobertas que fazem o próprio homem se alterar.

$\mathrm{Na}$ experiência moderna, a possibilidade de instaurar o homem num saber, o simples aparecimento dessa figura nova no campo da episteme, implica um imperativo que importuna interiormente o pensamento, pouco importa que ele seja cunhado sob as formas de uma moral, de uma política, de um humanismo, de um dever de se incumbir do destino ocidental, ou da pura e simples consciência de realizar na história uma tarefa de funcionário; o essencial é que o pensamento seja, por si mesmo e na espessura de seu trabalho, ao mesmo tempo saber e modificação de ser daquilo sobre o que se reflete. Ele põe em movimento, desde logo, aquilo que toca: não pode descobrir o impensado, ou ao menos ir em sua direção, sem logo aproximá-lo de si - ou talvez ainda, sem afastá-lo, sem que o ser do homem, em todo o caso, uma vez que ele se desenrola nessa distância, não se ache, por isso mesmo, alterado (FOUCAULT, 2002a, p. 452).

Evidenciamos aqui que a produção da Pedagogia como uma ciência somente é possível devido a essa reduplicação, não há como escaparmos dela. E nos parece que isso não é um problema a ser resolvido. Assim, a representação é a condição de possibilidade para a produção das nossas ciências, ou seja, por tratamos como nosso objeto aquilo que é nossa condição de possibilidade. 


\section{TECENDO ALGUMAS CONSIDERAÇÕES FINAIS: PROVOCAÇÕES À PEDAGOGIA COMO CIÊNCIA}

Ao iniciar esta última seção, queremos deixar claro que não tivemos a pretensão de anunciar caminhos que deveriam ser seguidos. Nossa pretensão foi colocar em suspenso algumas verdades que o discurso científico da Pedagogia produz e que têm efeitos no campo da Educação. Entendemos que o discurso da Pedagogia como Ciência nos habita, nos atravessa e faz parte da nossa caminhada profissional, não há como negar as marcas deixadas em nosso processo formativo. Aliás, não se trata disso! O que fizemos neste trabalho foi tentar escapar da ordem do discurso pedagógico arraigado por marcas da ciência moderna. Tentamos olhar de outra forma o campo da Educação e a da própria Pedagogia.

Nossa empreitada foi de questionar, de duvidar e de problematizar os enunciados produzidos pela Pedagogia e, para tanto, encontramos em Michel Foucault importantes ferramentas teóricas que nos possibilitaram desconfiar das consignas educacionais que pregam uma "racionalidade da prática", um "método científico", uma "ciência da prática educativa", uma "reflexão sobre a prática" e um "exame das práticas educativas". Nossa tentativa foi realizar um exercício de luta, de guerra com tais ditos tão potentes no campo da formação de professores.

Nesse trabalho não nos colocamos numa posição de neutralidade científica, muito pelo contrário, entendemos que a todo o momento constituímos e somos constituídas pelo objeto da pesquisa. Produzimos análises que fazem parte de nossos entendimentos, conviç̧ões e que não são escolhas ingênuas. Procuramos mergulhar na pesquisa, inserindo-nos nas discussões e nas problematizações; colocamo-nos, também, no movimento de pensar sobre elas. E nesse movimento elas também nos atravessam e nos produzem de alguma forma, já que entendemos que nossas escolhas não são livres, mas escolhas governadas por um conjunto de relações, de experiências e pelos próprios jogos de luta dos quais participamos.

Ao tentar colocar um ponto final nesse trabalho, muitas perguntas ficarão sem respostas. Assim, nosso convite é tentar produzirmo-nos por meio destes profissionais intelectuais, anunciados por Foucault, não sabendo muito bem o que será feito amanhã, mas encontrar possibilidades de pensamento, nos deslocar em outros campos e questionarmo-nos constantemente. Talvez este convite seja arriscado demais, mas só saberemos se o experenciarmos.

\section{REFERÊNCIAS}

CHRÉTHIEN, Claude. A ciência em ação: mitos e limites. Campinas, SP: Papirus, 1994.

FOUCAULT, Michel. História da Sexualidade I: a vontade de saber. 7. ed. Rio de Janeiro: Edições Graal, 1985.

Microfísica do Poder. 17. ed. Rio de Janeiro: Graal, 1990.

. O que é um autor? In.:

Ditos e escritos III - Estética: literatura e pintura, música e cinema. Rio de Janeiro: Forense Universitária, 2001.

As palavras e as coisas: uma arqueologia das ciências humanas. 8. ed. São Paulo: Martins Fontes, 2002a.

Vigiar e Punir: história da violência nas prisões. 25. ed. Petrópolis: Editora Vozes, 2002b.

A ordem do discurso. 10. ed. São Paulo: Edições Loyola, 2004.

Em defesa da Sociedade: curso no Collège de France (1975-1976). 4a tiragem. São Paulo: Martins Fontes, 2005.

Poder e saber. In.: Ditos e escritos IV - Estratégia, Poder-Saber. 2. ed. Rio de Janeiro: Forense Universitária, 2006.

Segurança, Território e População: curso no Collège de France (1977- 1978). São Paulo: Martins Fontes, 2008a. 
O Nascimento da Biopolítica. São Paulo: Martins Fontes, 2008b.

MACHADO, Roberto. Duas filosofias das Ciências do Homem. In.: CALOMENI, Tereza Cristina (org). Michel Foucault: entre o murmúrio e a palavra. Rio de Janeiro: Editora Faculdade de Direito de Campos, 2004.

\section{NOTAS}

1 Esta pesquisa conta com financiamento do CNPq.

2 PIMENTA, Selma Garrido. Pedagogia: ciência da Educação? 5. ed. São Paulo: Cortez, 2006.

3 FRANCO, Maria Amélia Santoro. Pedagogia como Ciência da Educação. 2. ed. São Paulo: Cortez, 2003.

4 A "Provinha Brasil" e o "Enem" são exemplos significativos destes exames que avaliam o desempenho dos alunos e, consequentemente, dos professores e da Escola.

5 Aqui podemos citar como exemplo Antônio Nóvoa, Selma Garrido Pimenta, José Carlos Libâneo, Maria Amélia Santoro.

6 Para destacar os excertos das obras analisadas, optamos por colocá-los em itálico.

Artigo recebido em 15/03/2013

Aprovado em 29/05/2013 